\title{
Os riscos da financeirização do microcrédito
}

\author{
Luccas Assis Attílio*
}

\section{Resumo}

\begin{abstract}
As políticas de liberalização financeira das décadas de 1970 e 1980 fizeram com que as finanças ganhassem proeminência no funcionamento de várias economias. Como um corolário, o fenômeno da financeirização emergiu e é marca do capitalismo contemporâneo. Todavia, a financeirização incorporou o microcrédito, instrumento que ganhou notoriedade na década de 1980 no combate à pobreza. Esse artigo é uma revisão da literatura que aponta riscos da entrada do microcrédito na lógica da financeirização.
\end{abstract}

Palavras-chave: Microcrédito. Financeirização. Liberalização financeira. Governo.

Código JEL: G21, O16, G10, G28.

* Graduado em Ciências Econômicas pela Universidade Federal de Viçosa. Mestre em Economia pela Universidade Federal de Minas Gerais. Professor de Economia da Universidade Federal de Ouro Preto. E-mail: luccas2014assis@gmail.com

http://dx.doi.org/10.5335/rtee.v22i47.6834

Submissão: 19/07/2016. Aceite: 23/09/2016. 


\section{Introdução}

A crescente financeirização da economia mundial é um fenômeno que há décadas desperta o interesse de alguns pesquisadores quanto às suas implicações no desempenho dos países. Aumento da disponibilidade do crédito, incorporação de agentes pobres no sistema financeiro, crescente endividamento privado e surgimento de ativos financeiros são marcas que caracterizam o atual estado do capitalismo na esfera financeira.

Pode-se depreender que a financeirização originou-se das políticas de liberalização financeira empreendidas em várias nações, principalmente, nas décadas de 1970 e 1980. Com a liberalização dos fluxos de capitais e maior liberdade financeira para as instituições, elas procuram explorar novos territórios no globo e incorporar maior número de clientes para ofertar seus serviços.

Em meio a esse processo, a pobreza era uma das mazelas sociais que contrastava com as partes prósperas das economias. O microcrédito tornou-se exemplo de combate à pobreza em Bangladesh por meio do Grameen Bank, em 1983, e desde então esse instrumento difundiu-se na economia global e é considerado mundialmente como política indispensável para reduzir o número de pobres. Todavia, se na década de 1980 o microcrédito era apoiado pelo Estado, nos anos seguintes o governo afastou-se dessa atividade, deixando-a a cargo das forças do mercado. ${ }^{1}$

Os riscos advindos com a liberalização financeira e a crescente financeirização da economia representam potenciais perigos para práticas financeiras que têm cada vez mais incorporado o microcrédito. Especulação, securitização, afastamento da relação de instituições financeiras com os clientes, manipulações de mercado, negligência com a produtividade de tais empréstimos e perda de foco no combate à pobreza são problemas corriqueiros envolvendo capitais no sistema financeiro, todavia, caso o microcrédito realmente seja englobado nos mercados financeiros como os demais capitais, os riscos citados tornam-se reais. É esse o objetivo do artigo, apontar canais pelos quais a financeirização do microcrédito pode representar riscos para os pobres. Ao mesmo tempo, ressaltamos que não estamos afirmando que o afastamento do microcrédito da esfera pública é algo prejudicial per si, tampouco que o Estado administrando esse serviço é uma panaceia. Apenas alertamos sobre possíveis ramificações dessa tendência.

Justifica-se esse trabalho em decorrência do debate atual sobre os efeitos do neoliberalismo sobre as economias (OSTRY; LOUNGANI; FURCERI, 2016). Esse artigo pretende proporcionar subsídios para essa questão na medida em que aponta 
riscos para uma guinada do microcrédito em direção à maior concorrência e menor intervenção pública.

A ideia é que a maior regulação financeira e a aproximação do Estado das atividades de microcrédito podem mitigar possíveis distorções ocasionadas pela financeirização desse instrumento. Baseou-se essa recomendação em função dos desequilíbrios que ocorreram devido à financeirização, que foi impulsionada pela liberalização financeira - tópico que é explorado no decorrer do artigo -, com o maior endividamento das famílias e o aprofundamento da busca pelo lucro financeiro.

O artigo está dividido em cinco seções, além desta introdução. Nas seções 2, 3 e 4 conceituam-se, respectivamente, os termos liberalização financeira, financeirização e microcrédito; na seção 5, apontam-se os riscos que podem ser transportados para o microcrédito e na seção 6 algumas considerações finais são articuladas.

\section{Liberalização financeira}

A liberalização financeira é um conjunto de medidas direcionadas para o segmento das finanças com a intenção de tornar os mercados financeiros mais integrados, abertos e dinâmicos. Seu surgimento ocorreu em um contexto de desempenho econômico errático por diversas nações na década de 1970, no qual vários Estados viram-se com baixo crescimento do produto, inflação persistente, aumento do desemprego e deterioração das contas internas e externas. No intuito de retirar esses países do estado combalido em que estavam, essas políticas econômicas focalizaram, primordialmente, em reduzir a participação do Estado na economia e deixar que as forças do mercado guiassem as ações dos agentes econômicos (SHAW, 1973; MCKINNON, 1973).

De acordo com Williamson e Mahar (1998), a liberalização financeira pode ser entendida sob seis dimensões, quais sejam: eliminação do controle de crédito, livre entrada no setor bancário e na indústria de serviços financeiros, autonomia para o funcionamento dos bancos, desregulamentação da taxa de juros, liberalização dos fluxos de capitais e bancos de propriedade privada. Vale ressaltar que para que determinado regime financeiro seja considerado liberalizado, ele não precisa contemplar todas essas características.

O controle do crédito foi debatido, pois consequências negativas para a economia, como corrupção, favorecimento político e ineficiente alocação, foram questionadas pelos adeptos da liberalização (MISHKIN, 2009). Ao retirar o controle desses empréstimos, esperava-se que segmentos excluídos do sistema financeiro fossem beneficiados com o instrumento. Em particular, setores produtivos da economia 
que não recebiam esse crédito passaram a recebê-lo, em detrimento de setores pouco produtivos, mas que contavam com suporte político para receber esses fluxos. A produtividade geral da economia tenderia, portanto, a recrudescer, conforme a distribuição desses créditos fosse guiada por argumentos estritamente econômicos (LEVINE, 1997).

A desregulamentação da taxa de juros combateria o baixo nível de poupança e de investimento e reduziria a volatilidade do consumo (HERMANN, 2003). Dessa forma, ao liberar a taxa de juros, aumentar-se-ia seu patamar, o que auxiliaria na estabilidade macroeconômica e reduziria o risco de choques inflacionários na economia (FRY, 1988).

O setor bancário de economias financeiramente fechadas era geralmente concentrado em poucas instituições e com reduzida concorrência, dando margem para práticas monopolistas e denotando pouco incentivo para que melhores métodos financeiros fossem desenvolvidos (DEMIRGUC-KUNT; LEVINE, 1996). A entrada de bancos estrangeiros, sobretudo em países em desenvolvimento, acarretaria o choque de gestão e eficiência, que; se no curto prazo poderia gerar efeitos deletérios para a economia doméstica (quebra de bancos domésticos, desemprego e; talvez; até queda no produto), no longo prazo traria benefícios estruturais que alavancariam o crescimento econômico (GOLDBERG, 2009; GRAHAN, 2004).

Conforme o governo exercia forte influência nesse regime, principalmente por meio dos bancos, a privatização passou a ser defendida (LEVINE; ZERVOS, 1998). $\mathrm{O}$ argumento subjacente a essa medida era de que as forças do mercado melhor guiariam a economia, pois considerariam o custo e benefício das opções disponíveis; novamente, é a crença dos argumentos econômicos se sobrepondo aos políticos. Entretanto, cabe ressaltar que as privatizações dos bancos estavam inseridas em um processo de maior escopo, que foram as privatizações de várias empresas estatais (CHANG; GRABEL, 2004).

Um corolário da última característica era conceder maior autonomia operacional para os bancos, incluindo o banco central (ROGER, 2009), que deveria adquirir credibilidade perante os agentes e combater a inflação, o que não seria uma tarefa de difícil realização, caso lograsse confiança no mercado. Para tal empreitada, a instituição passou a utilizar precipuamente o regime de metas inflacionárias. Nesse regime, a autoridade monetária focaliza sua política monetária em determinado patamar da inflação, por vezes, tendo uma margem de tolerância de $1 \%$ a $3 \%$, variando conforme o país (EPSTEIN; YELDAN, 2008). A ênfase no combate à inflação é uma marca da liberalização financeira, uma vez que durante o fordismo o foco centrava em políticas para o pleno emprego (BOYER, 2000). O mesmo pode ser dito em relação ao comportamento do banco central, que, de agente fomentador do crescimento 
econômico por intermédio de variadas ferramentas intervencionistas, passou a operar principalmente na questão concernente à inflação (EPSTEIN, 2013).

O último traço é a liberalização dos fluxos de capitais, ou seja, a retirada de controles da conta de capital. Talvez esse seja o ponto mais simbólico do processo de liberalização financeira (MISHKIN, 2009). A eliminação de controles traria novas fontes de financiamento, maior liquidez e baratearia o custo desses capitais, não deixando de citar que o governo teria de ser mais disciplinado para que esses influxos ocorressem em seu território (FRY, 1988).

O objetivo dessa seção foi demonstrar que a liberalização financeira representou o passo inicial para que o processo de financeirização pudesse emergir. Conforme os mercados financeiros passaram a ser mais integrados, desregulamentados e abertos, o comportamento dos agentes neles inseridos modificou-se gradualmente. Portanto, a financeirização da economia deve ser entendida como uma consequência do processo da liberalização financeira.

\section{Financeirização}

Algumas características da financeirização são relacionadas com a liberalização financeira, como o ganho de importância do setor financeiro sobre o setor real da economia (PALLEY, 2007). Isso é percebido pelo aumento dos lucros do setor financeiro e a proeminência dos juros na remuneração dos fatores de produção. Traduzindo em números, na economia dos Estados Unidos da América, entre os anos de 1970 e 1978, os lucros financeiros foram de $47 \%$ dos lucros totais, subindo para 68\% no período de 1979 a 2003 (BEITEL, 2009).

As instituições financeiras passaram a aumentar de tamanho com fusões e aquisições, principalmente a partir da década de 1970, recrudescendo os seus escopos da mesma forma (DYMSKI, 2012). Novamente utilizando números para elucidar essa tendência, em 1990 as dez maiores instituições financeiras dos EUA possuíam 10\% de todos os ativos financeiros da nação, subindo para 60\% em 2008. Globalmente, o fenômeno é de igual forma perceptível; maiores bancos globais possuíam 59\% dos ativos financeiros globais em 2006, passando para 70\% em 2010 (FOSTER, 2010).

Um ponto chave é a crescente participação dos trabalhadores no mundo das finanças. Crédito para consumo, hipotecas, educação ou saúde, juntamente com a provisão de ativos financeiros (seguro, pensão, habitação, fundos financeiros) são uma marca nesse processo. Fatores como a estagnação dos salários reais, desigualdade de renda e redução do papel do governo como estado de bem-estar social 
contribuíram para que as pessoas recorressem ao crédito para manter determinado padrão de vida. Nos EUA, o total de crédito como proporção do produto interno bruto subiu de $140 \%$ para $328,6 \%$ de 1973 a 2005 (PALLEY, 2007).

A entrada das finanças na vida social e individual dos indivíduos é interpretada por Lapavitsas (2009) como expropriação financeira. À medida que bancos comerciais passam a agir como BANCOS de investimento (receita financeira advém de comissões, taxas e securitizações) e miram o segmento pobre e excluído do mercado financeiro, o autor denota que a extração de lucros financeiros dessa classe é a expropriação, um novo tipo de exploração do trabalhador no capitalismo do século XXI. Por conseguinte, e considerando a crescente desigualdade de renda, a desconexão dos ganhos de produtividade com aumentos salariais reais, redirecionamento da política econômica a favor dos mercados financeiros e as inúmeras crises financeiras que eclodiram, a financeirização é relacionada com tensões, desequilíbrios e explorações (LAPAVITSAS, 2009; KRIPPNER, 2005).

$\mathrm{O}$ redirecionamento da política econômica ocorre devido à busca de credibilidade no mercado financeiro, que passa a valorizar medidas que restrinjam o aumento da inflação, déficits públicos e deterioração das contas externas. Em comparação ao fordismo, ocorre o abandono da meta de pleno emprego em prol da baixa inflação, guinada que vai ao encontro dos interesses da elite financeira (PALLEY, 2007). Sotiropoulos e Lapatsioras (2014) compreendem essas políticas econômicas circunscritas a uma nova governabilidade que o mercado financeiro impôs, qual seja, de manter o poder e a riqueza para as elites.

A alteração do comportamento das corporações não financeiras - que focalizam em lucros financeiros em detrimento de ganhos produtivos -, a crescente especulação financeira por meio, principalmente, de derivativos, preços de ativos baseados em rumores, sentimentos e manipulação, alastramento do crédito abastecendo bolhas financeiras e a redução da regulação do sistema financeiro aumentam a fragilidade financeira (BRYAN; MARTIN; RAFFERTY, 2009; LUCARELLI, 2012), processo que se corporificou em crises financeiras que afligiram a economia global, como a mexicana, em 1994, asiática, em 1997, russa, em 1998, brasileira, em 1999, e norte-americana, em 2007, e o estresse dos mercados financeiros como o da Rússia no final de 2014.

Sucintamente, a financeirização pode ser entendida pela entrada dos trabalhadores nas finanças, o alastramento do crédito na economia, a proeminência do setor financeiro sobre o setor real, o acúmulo de dívidas privadas pelos agentes econômicos, a nova operacionalização do mercado financeiro e o comportamento de curto prazo pelos participantes desses mercados, que buscam primordialmente 
lucros financeiros. Os riscos intrínsecos da financeirização, que podem se exacerbar com a adesão do microcrédito nesse processo, serão explanados na seção 5 .

\section{Microcrédito}

Desde as operações de microcrédito do Grameen Bank em 1983, esse tipo de atividade cresceu em escala e escopo em várias economias em volta do globo. Impulsionado pelo Prêmio Nobel da paz para Yunus em 2006, o microcrédito foi defendido como ferramenta eficaz no combate à pobreza e desigualdade de renda. Entre os seus defensores, o próprio Yunus (2000) assinala que as pessoas são pobres não devido à baixa escolaridade ou ausência dela, mas por causa do acesso ao capital, aquele que detém seu controle possui melhores meios de prosperar na vida. Como se observará ao longo dessa seção, a própria definição de pobreza implica controvérsia no uso do microcrédito como meio de superar esse gargalo social, além de diferentes correntes econômicas interpretarem esse tipo de empréstimo de modo distinto.

Nos anos 1950, 1960 e 1970 os agentes pobres eram vistos primordialmente como sendo familiares de fazendeiros em condições econômicas pouco abastadas; na década de 1980 passou a ter como foco as mulheres e seus dependentes; de 1990 em diante, porém, - e denotando uma evolução no conceito de pobreza -, classificar grupos como de pobres foi percebido como algo mais complexo e difícil de ranquear, dada a heterogeneidade dos agentes envolvidos (ELLIS, 2000). Concomitantemente com a análise dos grupos de pobreza, a maneira de empregar o microcrédito sofreu mudanças, tanto na forma de ser disponibilizado - deixando de ser subsidiado pelo Estado nos anos 1980 para ser guiado pelos mercados -, quanto no público-alvo - de dependentes de fazendeiros para diferentes atribuições de o que seria considerado como indivíduo pobre (MATIN; HULME; RUTHERFORD, 2002).

No eixo econômico, o pobre era caracterizado pela pouca atenção recebida pelos economistas (MATIN; HULME; RUTHERFORD, 2002). Por vezes, visto como incapaz de empreender atividades lucrativas, manusear uma carteira de crédito ou gerenciar o seu negócio, essas pessoas da classe de renda mais pobre ficaram por anos sem receber maiores atenções dos formuladores de política econômica. Como consequência dessa negligência, instrumentos para auxiliá-los a ascender socialmente eram pouco desenvolvidos (CHLIOVA; BRINCKMANN; ROSENBUSCH, 2014).

Foi nesse estado das artes que o Grameen Bank teve o mérito de combater a questão da pobreza com o uso do sistema financeiro. Fornecendo créditos com taxa de juros abaixo do nível de mercado, recebendo retornos desses desembolsos 
pelos tomadores e auxiliando inúmeras famílias que não possuíam colaterais para garantir o empréstimo a ascender de condição social, essa instituição despertou o interesse de vários políticos (CHLIOVA; BRINCKMANN; ROSENBUSCH, 2014; MICK, 2003). Acoplado a isso - e diferentemente do comportamento dos bancos convencionais -, muitas vezes são os agentes das instituições de microcrédito (IMCs) que se deslocam até o cliente para ofertar o serviço (SILVA, 2012).

$\mathrm{O}$ microcrédito pode ser usado para o beneficiário aproveitar de alguma oportunidade de negócio vislumbrada, suavizar seu consumo, aumentar seu padrão de vida, em casos de emergência médica, morte prematura de algum membro da família, roubo, para melhorar a segurança, na prevenção de riscos naturais, despesas com partos, casamento, no envelhecimento e na construção de ativos, ou seja, essa ferramenta permite ao pobre atingir determinados objetivos sociais de sua vida (MATIN; HULME; RUTHERFORD, 2002). A variedade de possibilidades que advém com o microcrédito ajuda a entender seu maciço aumento, que atinge mais de 205 milhões de pessoas desde 2010 (MAES; REED, 2012).

Essa amplitude de possíveis usos do microcrédito, entretanto, é vista de diferentes formas por algumas correntes da economia (SILVA, 2012). Os neoliberais tendem a ver o microcrédito como instrumento para reduzir a desigualdade criada pelo mercado. Nesse caso, é uma concepção de compensação pelas falhas da economia de mercado (MICK, 2003). A concepção emancipatória interpreta o microcrédito como meio para aumentar a igualdade e a solidariedade entre os agentes, criando novos campos sociais que possam promover maior cooperação pelas pessoas envolvidas (SILVA, 2012). A abordagem marxista denota que o microcrédito não altera a lógica intrínseca do capitalismo, que é a exploração do trabalho pelo capital, o que ocorre é somente a apropriação do capital por agentes excluídos do seu uso, e eles podem vir a explorar outros destituídos do capital (PANIAGO, 2008).

$\mathrm{O}$ microcrédito, além da dificuldade de consenso entre as correntes, sofre com a questão de combate à pobreza. Conforme Bangladesh testemunhou significativa redução desse problema social com a prática do microcrédito, a relação microcrédito/pobreza passou a ser vista como uma panaceia para extirpar essa mazela que aflige várias nações. Entretanto, alguns autores colocam-se contra essa relação, como é o caso de Hulme (2000), Bateman e Chang (2012) e Matin, Hulme e Rutherford (2002). Hulme (2000) defende que o microcrédito não atinge a camada mais necessitada desse tipo de instrumento, pelo contrário, muitos receptores do empréstimo já possuíam previamente um padrão de vida confortável. Para corroborar o seu ponto, o autor demonstra em seu estudo que o Quênia, nação africana caracterizada por enfrentar problemas sociais e econômicos, sobretudo relativos à 
pobreza, possui aproximadamente 10 milhões de pessoas na condição de pobres, todavia, menos de 70 mil delas tiveram acesso ao microcrédito.

Bateman e Chang (2012) explanam de forma mais elucidativa a razão da pobreza não ser reduzida, sendo em alguns casos até incrementada pelo microcrédito. Fatores como a negligência com a economia de escala pelas microempresas, incentivo ao aumento da oferta de produção dessas firmas, desconsiderando que a demanda para os produtos desse segmento de mercado esteja estagnada e falhas em conectar microempresas de um mesmo setor para trabalharem cooperativamente, ajudam a entender o insucesso do microcrédito em algumas regiões. Ademais, o fracasso de tais empreitadas é custoso para os tomadores, que se endividam, perdem ativos, deixam de ter os seus sustentos mínimos e vendem o que têm a preços irrisórios. O custo de oportunidade é alto para as pessoas que estão na linha da pobreza.

Destarte, considerar o microcrédito como a solução para a pobreza parece pouco plausível, uma vez que a pobreza é uma questão mais complexa e que para a sua superação outros mecanismos devem ser traçados. Além disso, como assinalam Chliova, Brinckmann e Rosenbusch (2014), a eficácia do microcrédito varia dependendo do contexto em que ele é empregado, ou seja, para cada localidade um estudo compreendendo as peculiaridades seria o recomendável antes de empreender esses empréstimos, dado os custos sociais citados anteriormente. Em resumo, one size fits all não parece ser válido.

\section{Os riscos da disseminação do microcrédito no contexto da financeirização}

O comportamento de curto prazo das corporações que estão envolvidas no mercado financeiro reflete-se nas instituições de microcrédito, que securitizam e comercializam o microcrédito para auferir lucros financeiros. A securitização permite que a IMC empreenda novos créditos sem que tenha recebido pelo primeiro desembolso, transferindo o risco para outros agentes. Esse tipo de operação foi um dos fatores que deflagrou a crise das hipotecas subprime nos EUA em 2007 (AITKEN, 2013).

A lógica do lucro financeiro incentiva as IMCs a efetuar inúmeros créditos com base em padrões de viabilidade e lucratividade financeira, distanciando, portanto, do interesse de mitigar a pobreza (AITKEN, 2013). O microcrédito, bem como o crédito, tornou-se um fim para ele mesmo, ou seja, pouco interessa o seu impacto na vida dos receptores ou quais agentes irão recebê-lo, o que importa é a 
sua comercialização e o surgimento de lucros financeiros. Infere-se, pois, que uma das características do microcrédito, de que os agentes que fornecem o empréstimo se desloquem até os potenciais destinatários, está sendo erodida por esse processo. $\mathrm{O}$ agente beneficiário está perdendo contato com a instituição que fornece $\mathrm{o}$ capital. Redução da informação disponível sobre os clientes e dificuldade em avaliar os riscos dessas operações são consequências que podem emergir com esse hiato (LUCARELLI, 2012).

A redução do rigor com o crédito para a sua liberação é outro risco que existe no sistema financeiro e que pode ser transmitido para o microcrédito. De forma parecida com as consequências dos empréstimos hipotecários norte-americanos da década passada, a redução do rigor pode colocar a população pobre em pior situação que a priori. Os empréstimos ajustáveis (Adjustable Rate Mortgages) exerceram um importante papel no desencadeamento da crise de 2007 na medida em que os seus juros cobrados subiram e deixaram seus tomadores em situação desfavorável, tomadores que pertenciam a uma classe de renda frágil (LAPAVITSAS, 2009). Na esfera do microcrédito, e dado que os seus tomadores se caracterizam por ser agentes vulneráveis, o risco torna-se ainda maior. $\mathrm{E}$ se for considerado que a crescente securitização do microcrédito incorpora essa redução no rigor do crédito, juntamente com o fato da transferência dos riscos, a piora na situação das famílias pobres, que em última instância são os que apoiam a base de toda a operação de securitização, pode acarretar instabilidades no sistema financeiro.

A estagnação dos salários reais, o crescente endividamento das famílias, a redução das provisões do governo devido ao enfraquecimento do estado de bem-estar social, a flexibilidade no mercado de trabalho e os mercados informais saturados que causam a queda dos preços, lucros e salários das microempresas, podem ser os ingredientes que deflagrem uma possível crise financeira no segmento do microcrédito (BATEMAN; CHANG, 2012; LAPAVITSAS, 2011; PALLEY, 2007). E como foi explanado que o microcrédito tem sido securitizado e comercializado, o risco pode se alastrar e afetar outras áreas da economia. Esse risco pode ser englobado na afirmação de Boyer (2000) de que a difusão das finanças pode colocar a economia em uma zona de instabilidade estrutural.

Em alguns casos, 90\% de todo o microcrédito liberado por uma IMC é direcionado para o consumo (BATEMAN, 2010). Essa é uma tendência que ocorre nesse segmento do sistema financeiro, pois além de tentar aquecer a economia com a demanda agregada, o crédito permite o aumento do consumo para níveis que ultrapassem a restrição orçamentária. Ademais, deve-se se ater à lógica do capitalismo pela busca do lucro, em particular, lucros financeiros (MARX, 1968). E 
nesse contexto, as IMCs usam o crédito para auferir lucros, embora esse processo tenha limites, uma vez que o endividamento dos agentes privados esbarra em novos limites.

Na financeirização, a produtividade não é a peça central conforme foi durante o fordismo (BOYER, 2000). A implicação disso para o domínio do microcrédito é que ele não foi primordialmente pensado em termos de economias de escala pelas microempresas, interação entre elas e eficiência, mas, sim, com base nos lucros financeiros pelos agentes que o disponibilizam. A negligência com a produtividade mostrou seus efeitos em alguns países, como é o caso de falências de instituições de microcrédito no Marrocos, no México, na Nicarágua, no Paquistão, na Bósnia e na Índia (BATEMAN; CHANG, 2012; ARUNACHALAM, 2011).

Matin, Hulme e Rutherford (2002) defendem que o alastramento do microcrédito pode permitir que o pobre especulasse, analisando esse fenômeno como algo positivo. O presente artigo discorda dessa visão, dado que a especulação tem causado vários danos no lado real da economia, o que pode ser percebido nas inúmeras crises financeiras que emergiram desde a liberalização financeira (GRABEL, 1995; STIGLITZ, 1989; STIGLITZ, 2000). A especulação tende a separar ainda mais as finanças da economia real (SOTIROPOULOS; LAPATSIORAS, 2014). Ademais, a especulação financeira pelo pobre é outro risco que a financeirização do microcrédito pode desencadear.

$\mathrm{O}$ alastramento do microcrédito fez com que agências de classificação de microcrédito surgissem, tais como a MicroRate, Planet Rating e Micro Credit Rating International (AITKEN, 2013). O risco da emergência dessas instituições é uma possível analogia com as agências de classificação de crédito que erraram na avaliação dos títulos hipotecários subprime na crise de 2007; denotando bons ratings para títulos de caráter duvidoso, essas agências incentivaram a comercialização desses ativos, o que se concretizou em uma bolha imobiliária. Alguns autores denotam que essas instituições foram pressionadas por bancos para fornecerem avaliação favorável a tais títulos (GOWAN, 2009), enquanto outros questionam possíveis subornos (LAPAVITSAS, 2009). Todavia, a hipótese de que essas agências não conseguiram compreender o sistema financeiro, bem como seus riscos, não pode ser descartada, dada a complexidade desse mercado. Desse modo, o mercado de microcrédito está sujeito a riscos similares.

A financeirização utiliza-se do microcrédito para se perpetuar e se alastrar em segmentos não explorados da economia. Ao fazer isso, ela transporta falhas do sistema financeiro para as famílias pobres servindo-se de conceitos teóricos de combate à pobreza como véu para justificar práticas pró-lucro. Portanto, o microcrédito 
pode ter se afastado do seu ideal de combate à pobreza e aproximou-se cada vez mais da lógica do lucro, não obstante trazendo potenciais riscos para a população mais pobre.

As crises financeiras que eclodiram com a liberalização financeira e a financeirização (com destaque para a crise de 2007) elucidam que o atual funcionamento do mercado financeiro deve se alterar para que uma maior estabilidade seja auferida pelos Estados. A incorporação do microcrédito nesse mercado reproduz o seu funcionamento, não obstante aumentando seus riscos. Desse modo, microcrédito e financeirização é uma relação que merece maior estudo para compreender os seus riscos e auxiliar na construção de políticas que minimizem os danos econômicos e maximizem os ganhos sociais.

\section{Considerações finais}

$\mathrm{O}$ artigo conceituou o termo liberalização financeira de modo a demonstrar que as políticas circunscritas nessa ideologia forneceram terreno para que a financeirização emergisse. $\mathrm{O}$ alastramento das finanças na economia é uma tendência que persiste nos dias atuais e que tem incorporado cada vez mais o microcrédito no seu escopo.

Os riscos apontados ao longo do artigo são críveis, ainda mais considerando que muitos deles engatilharam a crise de 2007 nos EUA. Portanto, é importante rever o funcionamento do microcrédito em um sistema econômico cada vez mais financeirizado.

Todavia, independentemente dos riscos apontados, uma reflexão deveria ocorrer sobre o afastamento do uso do microcrédito para fins sociais. Caso a crescente financeirização conseguisse mitigar a pobreza global com o uso do microcrédito, esse artigo perderia a sua essência, porém, não é o que se observa.

Maior regulação financeira e aproximação do Estado nas atividades de microcrédito são medidas que podem mitigar os possíveis riscos elencados nesse trabalho. Essa recomendação é baseada no período entre os anos posteriores ao fim da Segunda Guerra Mundial até a conjuntura de crise dos anos 1970 e 1980 . Nesse período, o maior controle das atividades financeiras pelo governo possibilitou o surgimento de um ambiente econômico mais estável. A resposta para minimizar os danos da financeirização do microcrédito pode estar nesse período. 


\title{
The risks of the microcredit financialization
}

\begin{abstract}
The financial liberalization policies of the 1970s and 1980s have provided the finances to gain prominence in the operation of various economies. As a corollary, the phenomenon of the financialization emerged and has been a trace of contemporary capitalism. However, the financialization has incorporated the microcredit, an instrument that gained notoriety in the 1980s to combat poverty. This article is a survey in which points risks of microcredit entry in the logic of financialization.
\end{abstract}

Keywords: Microcredit. Financialization. Financial liberalization. Government.

JEL Code: G21, O16, G10, G28.

\section{Los riesgos de la financiarización del microcrédito}

\section{Resumen}

Las políticas de liberalización financiera de los años 1970 y 1980 significaron que las finanzas ganaron prominencia en el funcionamiento de diferentes economías. Como corolario, el fenómeno de la financiarización ha surgido y tiene sido una marca distintivo del capitalismo contemporáneo. Sin embargo, la financiarización tiene incorporado microcréditos, un instrumento que ganó notoriedad en la década de 1980 para reducir la pobreza. Este artículo es una revisión de la literatura que señala riesgos de entrada de microcréditos en la lógica de la financiarización.

Palabras clave: Microcréditos. Financiarización. Liberalización financiera, Gobierno. 


\section{Nota}

1 No decorrer do artigo é explicado como ocorreu essa guinada pró-mercado.

\section{Referências}

AITKEN, R. The financialization of micro-credit. Development and Change, Oxford, v. 44, n. 3, p. 473-499, 2013.

ARUNACHALAM, R. The journey of Indian micro-finance: lessons for the future. Chennai: Aapti, 2011.

BATEMAN, M.; CHANG, H. J. Microfinance and the illusion of development: from hubris to nemesis in thirty years. World Economic Review, Bristol, v. 1, n. 1, p. 13-36, 2012.

BEITEL, K. The rate of profit and the problem of stagnant investment: a structural analysis of bankers to accumulation and the spectre of protracted crisis. Historical Materialism, Londres, v. 17 , p. $60-100,2009$.

BOYER, R. Is a finance-led growth regime a viable alternative to fordism? A preliminary analysis. Economy and Society, Londres, v. 29, n. 1, p. 111-145, 2000.

BRYAN, D.; MARTIN, R.; RAFFERTY, M. Financialization and Marx: giving labor and capital a financial makeover. Review of Radical Political Economics, Cairo, v. 41, n. 4, p. 458-472, 2009.

CHANG, H. J.; GRABEL, I. Reclaiming development: an alternative economic policy manual. London: Zed Books, 2004.

CHLIOVA, M.; BRINCKMANN, J.; ROSENBUSCH, N. Is microcredit a blessing for the poor? A meta-analysis examining development outcomes and contextual considerations. Journal of Business Venturing, Amsterdã, v. 30, n. 3, p. 467-487, 2014. Disponível em: <http://dx.doi. org/10.1016/j.jbusvent.2014.10.003>. Acesso em: 10 jan. 2015.

DEMIRGUC-KUNT, A.; LEVINE, R. Stock Market development and financial intermediaries: stylized facts. The World Bank Economic Review, Oxford, v. 10, n. 2, p. 291-321, 1996.

DYMSKI, G. A. O gênio fora da garrafa: a evolução da política too big to fail e a estratégia bancária dos Estados Unidos. In: CINTRA, M.; GOMES, K. (Ed.) As transformações no sistema financeiro internacional. Brasília: Instituto de Pesquisa Econômica Aplicada, 2012. p. 177-244.

ELLIS, F. Rural livelihoods. Oxford: Oxford University, 2000.

EPSTEIN, G. Developmental central banking: inning the future by updating a page from the past. Review of Keynesian Economics, Cheltenham, v. 1, n. 3, p. 273-287, 2013.

EPSTEIN, G.; YELDAN, E. Inflation targeting, employment creation and economic development: assessing the impacts and policy alternatives. International Review of Applied Economics, Oxford, v. 22, n. 2, p. 131-144, 2008.

FOSTER, J. B. The age of monopoly-finance capital. Monthly Review, New York, v. 61, n. 9, p. 1-11, 2010.

FRY, M. Money, interest, and banking in economic development. Baltimore. Johns Hopkins University, 1988. 
GOLDBERG, L. S. Understanding banking sector globalization. IMF Staff Papers, Washington, D.C, v. 56, n. 1, p. 171-197, 2009.

GOWAN, P. Crisis in the heartland: consequences of the new Wall Street system. Estudos Avançados, São Paulo, v. 23, n. 65, p. 49-72, 2009.

GRABEL, I. Speculation-led economic development: a post-keynesian interpretation of financial liberalization programmes in the third world. International Review of Applied Economics, Oxford, v. 9, n. 2, p. 127-149, 1995.

GRAHAN, E. M. Opening banking to foreign competition. In: LITAN, R. E.; MASSON, P.; POMERLEANO, M. (Ed.) Open doors: foreign participation in financial systems in developing countries. Washington, DC, Brookings Institutions Press, 2004.

HERMANN, J. O modelo de liberalização financeira dos anos 1990: restatement ou auto-crítica? Revista Nova Economia, Belo Horizonte, v. 13, n. 2, p. 137-172, 2003.

HULME, D. Is microdebt good for poor people? A note on the dark side of microfinance. Small Enterprise Development, Bingley, v. 11, n. 1, p. 26-28, 2000.

KRIPPNER, G. R. The financialization of the American economy. Socio-Economic Review, Oxford, v. 3, n. 2, p. 173-208, 2005.

LAPAVITSAS, C. Financialised capitalism: crisis and financial expropriation. Historical Materialism, Londres, v. 17, p. 114-148, 2009. 626, 2011.

Theorizing financialization. Work, Employment and Society, Cairo, v. 25, n. 4, p. 611-

LEVINE, R. Financial development and economic growth: views and agenda. Journal of Economic Literature, Pittsburgh, PA, v. 35, n. 2, p. 688-726, 1997.

LEVINE, R.; ZERVOS, S. Stock markets, banks, and economic growth. The American Economic Review, Nashville, v. 88, n. 3, p. 537-558, 1998.

LUCARELLI, B. Financialization and global imbalances: prelude to crisis. Review of Radical Political Economics, Cairo, v. 44, n. 4, p. 429-447, 2012.

MAES, J. P.; REED, L. R. State of the Microcredit Summit Campaign Report. 2012. Washington, DC, 2012.

MARX, K. O capital: crítica da economia política. Rio de Janeiro: Civilização Brasileira, 1968. V. 1.

MATIN, I.; HULME, D.; RUTHERFORD, S. Finance for the poor: from microcredit to microfinancial services. Journal of International Development, Hoboken, v. 14, n. 2, p. 273-294, 2002.

MCKINNON, R. Money and capital in economic development. Washington, DC: Brookings Institution, 1973.

MICK, J. O caráter social do crédito: microcrédito, combate à pobreza e desenvolvimento alternativo. Tese (Doutorado em Sociologia Política) - Universidade Federal de Santa Catarina, Florianópolis, 2003, p. 1-254.

MISHKIN, F. S. Why we shouldn't turn our backs on financial globalization. IMF Staff Papers, Washington, DC, v. 56, n. 1, p. p. 139-170, 2009.

OSTRY, D., LOUNGANI, P.; FURCERI, D. Neoliberalism: oversold? Finance \& Development, Washington, DC, v. 53, n. 2, p. 38-41, 2016. 
PALLEY, T. I. Financialization: what it is and why it matters. The Levy Economics Institute. Working Paper, n. 525, p. 1-31, 2007.

PANIAGO, M. C. Os meios que se perderam dos fins: Cooperativas fabris e autogestão de trabalhadores. Revista Outubro, Curitiba, n. 17, p. 1-18, 2008.

ROGER, S. Inflation targeting at 20: achievements and challenges. IMF Working Papers, Washington, D.C. n. 9/236, p. 1-31, 2009.

SHAW, E. S. Financial deepening in economic development. New York: Oxford University, 1973.

SILVA, R. A. Microcrédito e suas relações com o desenvolvimento local: um estudo de caso sobre o banco da família. Monografia (Graduação em Ciências Econômicas) - Universidade Federal de Santa Catarina, Florianópolis, 2012.

SOTIROPOULOS, D. P.; LAPATSIORAS, S. Financialization and Marx: some reflections on Bryan's, Martin's and Rafferty's argumentation. Review of Radical Political Economics, Cairo, v. 46, n. 1, p. 87-101, 2014.

STIGLITZ, J. E. Financial markets and development. Oxford Review of Economic Policy, Oxford, v. 5 , n. 4 , p. 55-68, 1989.

Capital market liberalization, economic growth, and instability. World Development, Washington, D.C, v. 28, n. 6, p. 1.075-1.086, 2000.

WILLIAMSON, J.; MAHAR, M. A Survey of financial liberalization. Essays in International Finance, Princeton, n. 211, p. 1-74, 1998.

YUNUS, M. O banqueiro dos pobres. São Paulo. Ática, 2000. 